\title{
Photopletismographic Method for Determining Rigidity of Vascular Wall in Patients with Myocardial Infarction with Atrial Fibrillation
}

\author{
NN Neobutov* and SV Kolbasnikov \\ GBOU VPO Tver State Medical University of the Ministry of Health of Russia, Russia
}

*Corresponding author: Nikolai Neobutov, GBOU VPO Tver State Medical University of the Ministry of Health of Russia,

Tver, Russia

\begin{tabular}{lll}
\hline ARTICLE INFO & & ABSTRACT \\
\cline { 1 - 1 } $\begin{array}{l}\text { Received: 幽 June 04, } 2020 \\
\text { Published: 幽 June 22, } 2020\end{array}$ & $\begin{array}{l}\text { Citation: NN Neobutov, SV Kolbasnikov. Photopletismographic Method for Determin- } \\
\text { ing Rigidity of Vascular Wall in Patients with Myocardial Infarction with Atrial Fibrilla- } \\
\text { tion. Biomed J Sci \& Tech Res 28(3)-2020. BJSTR. MS.ID.004647. }\end{array}$ \\
\hline
\end{tabular}

\section{Short Communication}

\section{Objective}

To evaluate the parameters of the pulse wave contour analysis and endothelial function in patients with myocardial infarction in various forms of atrial fibrillation.

\section{Materials and Methods}

138 patients ( 63 men, 75 women) who were hospitalized in the cardiology department of the City Clinical Hospital No. 7 GBUZ with a diagnosis of myocardial infarction with atrial fibrillation were examined. Depending on the form of atrial fibrillation, the patients were divided into 2 groups: the 1 st consisted of $83(60.1 \%)$ patients with a paroxysmal form, the 2nd group - 55 (39.9\%) with a constant form

\section{Conducted}

General clinical examination, studied the localization of myocardial infarction, its frequency (primary, repeated) [1-6], complications (acute left ventricular failure according to Killip, 1967) [1]. The stiffness of the vascular wall was studied by the photoplethysmographic method (Angioscan-1 apparatus). Based on the contour analysis of the photoplethysmogram [4], the following were estimated: heart rate (PE; bpm), stiffness index (SI - Stiffness index; m / s), reflection index (RI - Reflection Index;\%), amplitude occlusion index (IOA ;\%), the increase index (Alp Augmentation index;\%), the increase index normalized for heart rate ( $\mathrm{PP}=75$ ) (Alp 75 - Augmentation index @ HR = 75), age index (AGI - Aging Index), age of the vascular system (VA - Vascular Aging; years), systole duration (ED - Ejectuon Duration; m / s), pulse wave duration (PD - Pulse Duration; m / s), central systolic pressure (Spa - Systolic Pressure - Aortic - prognosis, mm Hg), type of pulse wave $(A, B, C)$. To assess endothelial function, a test was performed with reactive hyperemia with the calculation of the amplitude occlusion index (IOA; conventional units) and phase shift (SF; ms) between the channels.

\section{Results}

Among patients of the 1st group (age $71.9 \pm 8.9$ years), anterior myocardial infarction was recorded in 33 (39.7\%), the lower one in $20(24.3 \%)$, and the second anterior one in $15(18,0 \%)$, repeated lower - in 15 (18.0\%) examined. In patients of the 2nd group (age - $73.7 \pm 9.0$ years), anterior myocardial infarction occurred in 25 (45.4\%) people, lower myocardial infarction - in 17 (30.9\%), repeated anterior - in $11(20.0 \%)$ people, repeated lower - in 2 (3.6\%). In patients with a paroxysmal form of atrial fibrillation, I and II prevail, less often III and IV, the functional class of acute heart failure, while in patients with a constant form of atrial fibrillation, the frequency of II and III increased, with a decrease in the functional class I and IV.

In patients with a constant form of atrial fibrillation, there was a significant increase in PD $600.9 \pm 16.2 \mathrm{~m} / \mathrm{s}(\mathrm{p}<0.05)$, a decrease in RI of $21.2 \pm 2.3 \%$ ( p < 2.05$)$, as well as tendency to increase AGI $1.1 \pm 0.4$, SI $8.7 \pm 1.8 \mathrm{~m} / \mathrm{s}$, decrease ED $40.4 \pm 7.9 \%$, compared with patients with a constant form of atrial fibrillation (respectively, PD $541.0 \pm 9.4 \mathrm{~m} / \mathrm{s}$, RI $32.2 \pm 1.7 \%$, AGI $0.8 \pm 0.2$, SI $7.8 \pm 2.0 \mathrm{~m} / \mathrm{s}$, 
ED $45.2 \pm 1.0 \%$ ), which indicates a high tone of the small muscle arteries. In the studied groups, an increase in the frequency of a pulse wave of type A and B was observed, which characterizes a decrease in the elasticity of the vascular wall. However, in individuals with a constant form of atrial fibrillation, the frequency of waves A $(78.4 \pm 5.0 \%)$ and B $(15.1 \pm 3.4 \%)$ were higher than in individuals with a paroxysmal form (respectively $72.1 \pm 4,2 \%$; 19.2 $\pm 3.6 \%$ ), which indicates a significant increase in afterload and a violation of diastolic myocardial relaxation. In patients of the 2 nd group there was a statistically significant decrease in SF ( - $12.2 \pm$ $2.6 \mathrm{~ms}$; ( $\mathrm{p}<0.05)$, as well as a tendency to decrease IOA (1.15 \pm 0.6 conventional units), compared with patients of the 1st group (respectively, $3.7 \pm 0.9 \mathrm{~ms}$ and $1.4 \pm 0.7$ conv.ed), which indicates significant impairment of endothelial function in large muscle arteries.

\section{Conclusion}

In patients with myocardial infarction with a constant form of atrial fibrillation, in contrast to patients with a paroxysmal form,

ISSN: 2574-1241

DOI: $10.26717 /$ BJSTR.2020.28.004647

NN Neobutov. Biomed J Sci \& Tech Res

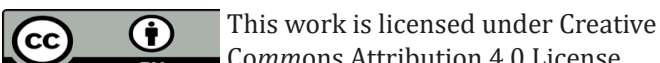

Submission Link: https://biomedres.us/submit-manuscript.php endothelial dysfunction is noted with a decrease in the elasticity of the arterial vascular wall, which must be taken into account when developing treatment and prevention programs and conducting medical and social examination.

\section{References}

1. (2012) AngioScan-01 Diagnostic complex for analyzing the state of the cardiovascular system: User Guide. Angio Scan Electronics Ltd, Moscow pp. 119.

2. Bennet DH (2010) Cardiac arrhythmias [Text]: pract rec / DH Bennett. In VA Sulimov (Eds.), ( $8^{\text {th }}$ Edn.), trans. from English MV Syrtsova, GEOTARMedia, Moscow pp. 440

3. Shakhnovich RM (2010) Acute coronary syndrome with ST segment elevation. In RM Shakhnovich (Eds.), GEOTAR-Media, Moscow pp. 372.

4. Killip T, Kimball JT (1967) Treament of myocardial infarction in a coronary care unit. A two-year experience with 250 patients. Am J Cardiol 20(4): 457-464

5. Schmitt J, Duray G, Gersh B (2009) Atrial fibrillation in acute myocardial infarction: A systematic review of the incidence, clinical features, and prognostic implications. Eur Heart J 30(9): 1038-1045.

6. Tilling L, Clapp B(2009) Atrial fibrillation in myo- cardial infarction: predictors and prognosis. Int J Clin Pract 63: 712-721.

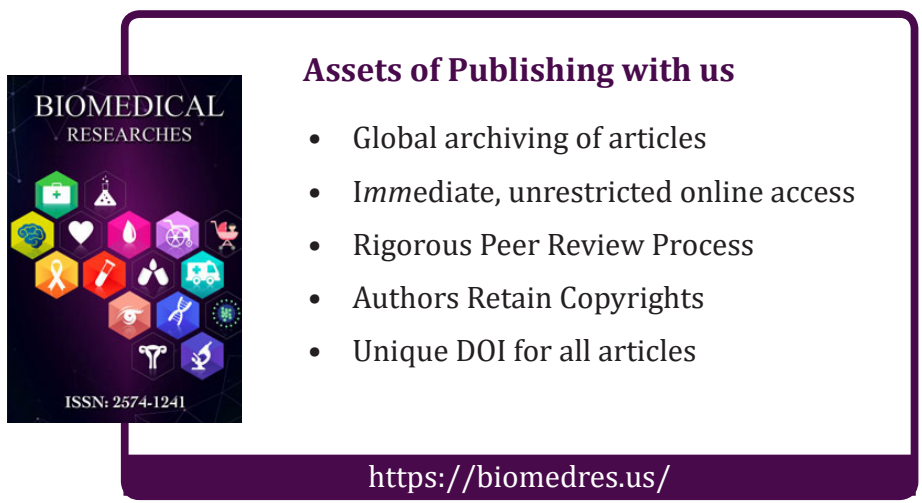

